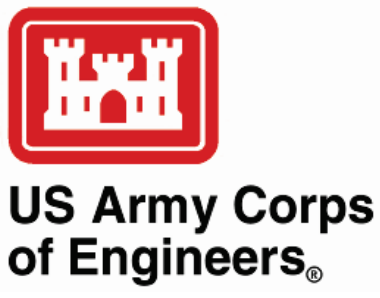

\title{
In Situ Measurements of Directional Wave Spectra from an Unmanned Aerial System
}

\section{by Clarence O. Collins III and Katherine Brodie}

PURPOSE: This Coastal and Hydraulics Engineering Technical Note (CHETN) describes the ability to measure the directional-frequency spectrum of sea surface waves based on the motion of a floating unmanned aerial system (UAS). The UAS used in this effort was custom built and designed to land on and take off from the sea surface. It was deployed in the vicinity of an operational wave sensor, the $8 \mathrm{~m}^{*}$ array, at the US Army Engineer Research and Development Center (ERDC), Field Research Facility (FRF) in Duck, NC. While on the sea surface, an inertial navigation system (INS) recorded the response of the UAS to the incoming ocean waves. Two different INS signals were used to calculate one-dimensional (1D) frequency spectra and compared against the $8 \mathrm{~m}$ array. Two-dimensional (2D) directional-frequency spectra were calculated from INS data using traditional single-point-triplet analysis and a data adaptive method. The directional spectrum compared favorably against the $8 \mathrm{~m}$ array.

BACKGROUND: Wave information is important to military operations in open and coastal seas (e.g., amphibious landings). Direct, in situ measurements are desirable but difficult and risky to make along austere coasts. A UAS that could covertly enter an austere environment, make in situ measurements, and return or telemeter the data would be a powerful tool. The Eagle, a UAS design based on this concept, was funded by the Office of Naval Research. It was developed by a collaborative group from Pennsylvania State, the US Naval Research Laboratory, and industry partners.

The Eagle is a quad-copter with dimensions $\sim 1.0 \mathrm{~m}$ from rotor to rotor and $\sim 0.1 \mathrm{~m}$ height (Figure 1). The wave measurements presented here use data from an onboard INS. The INS provides signals from the constituent sensors - gyroscope, accelerometer, augmented Global Positioning System (GPS), and magnetometer - and a product called Navstate ${ }^{\dagger}$ that combines and integrates these with thermistor and barometer data.

Wave measurements are routinely made using motion data from floating platforms, mostly buoys (e.g., Longuet-Higgins et al. 1963; Tucker and Pitt 2001; Collins 2012) but also ships (Tucker 1952; Collins et al. 2015), and Wave Gliders (Lenain and Melville 2014; Thomson et al. 2018). The Eagle UAS was not initially designed to measure waves; thus, its form factor bears no resemblance to typical wave measurement platforms. Traditionally, form and symmetry were thought to be critical components for measuring waves, but directional wave measurements have successfully been derived from asymmetric buoys (Collins et al. 2014), and thus it is worth exploring data from other non-traditional platforms.

\footnotetext{
* For a full list of the spelled-out forms of the units of measure used in this document, please refer to US Government Publishing Office Style Manual, 31st ed. (Washington, DC: US Government Publishing Office 2016), 248-52, https://www.govinfo.gov/content/pkg/GPO-STYLEMANUAL-2016/pdf/GPO-STYLEMANUAL-2016.pdf.

${ }^{\dagger}$ For more details, please contact E. Johnson (Pennsylvania State University) at eric.johnson@psu.edu.
} 


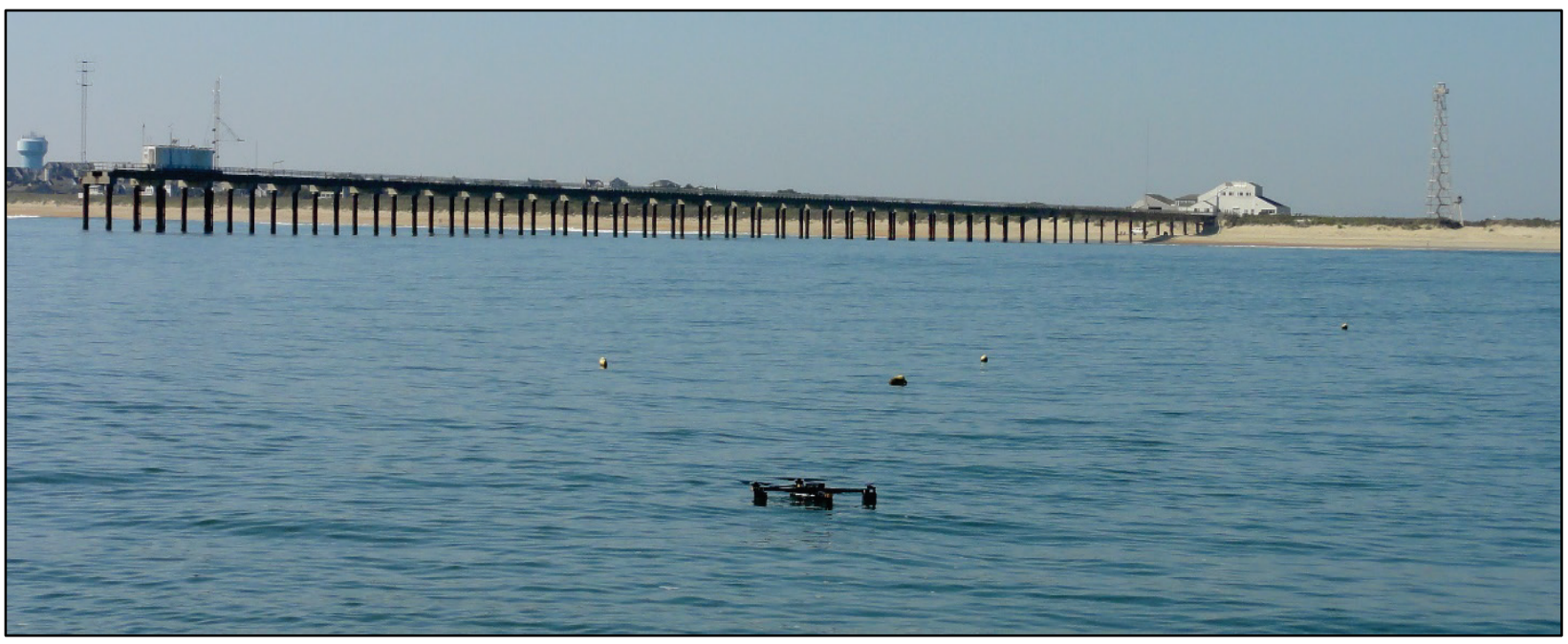

Figure 1. The Eagle AUS on the sea surface over the $8 \mathrm{~m}$ array at the FRF.

Based on current information, this is the first presentation of in situ, spectral wave measurements from a UAS platform. This a particularly useful and timely contribution as UASs are quickly becoming ubiquitous research platforms. Related measurements from UAS include remotely sensed coastal imagery (Holman et al. 2017) from which bathymetry can be derived from wave speed (Brodie et al. 2019), and remotely sensed wave spectra (e.g., Reinenman et al. 2013; Yurovskaya et al. 2018).

EXPERIMENT: An experiment was conducted on October 5, 2018, approximately 14:30 UTC, at the ERDC FRF in Duck, NC. The Eagle was hand deployed off the side of a LARC* vessel directly over the $8 \mathrm{~m}$ array (e.g., Long and Oltman-Shay 1991). The Eagle's rotors were powered down, and it was allowed to slowly and freely drift towards the south for a little over 20 min while motion data were recorded. Figure 2 shows a map of the area with the elements of the $8 \mathrm{~m}$ array and the drift path of the Eagle. The waves were $\sim 0.8 \mathrm{~m}$ (significant wave height) swell out of the east, and the winds light. An anemometer located on the end of the pier indicated a wind speed of $\sim 4.6 \mathrm{~m} / \mathrm{s}$ from the south.

\footnotetext{
* Lighter Amphibious Resupply Cargo
} 


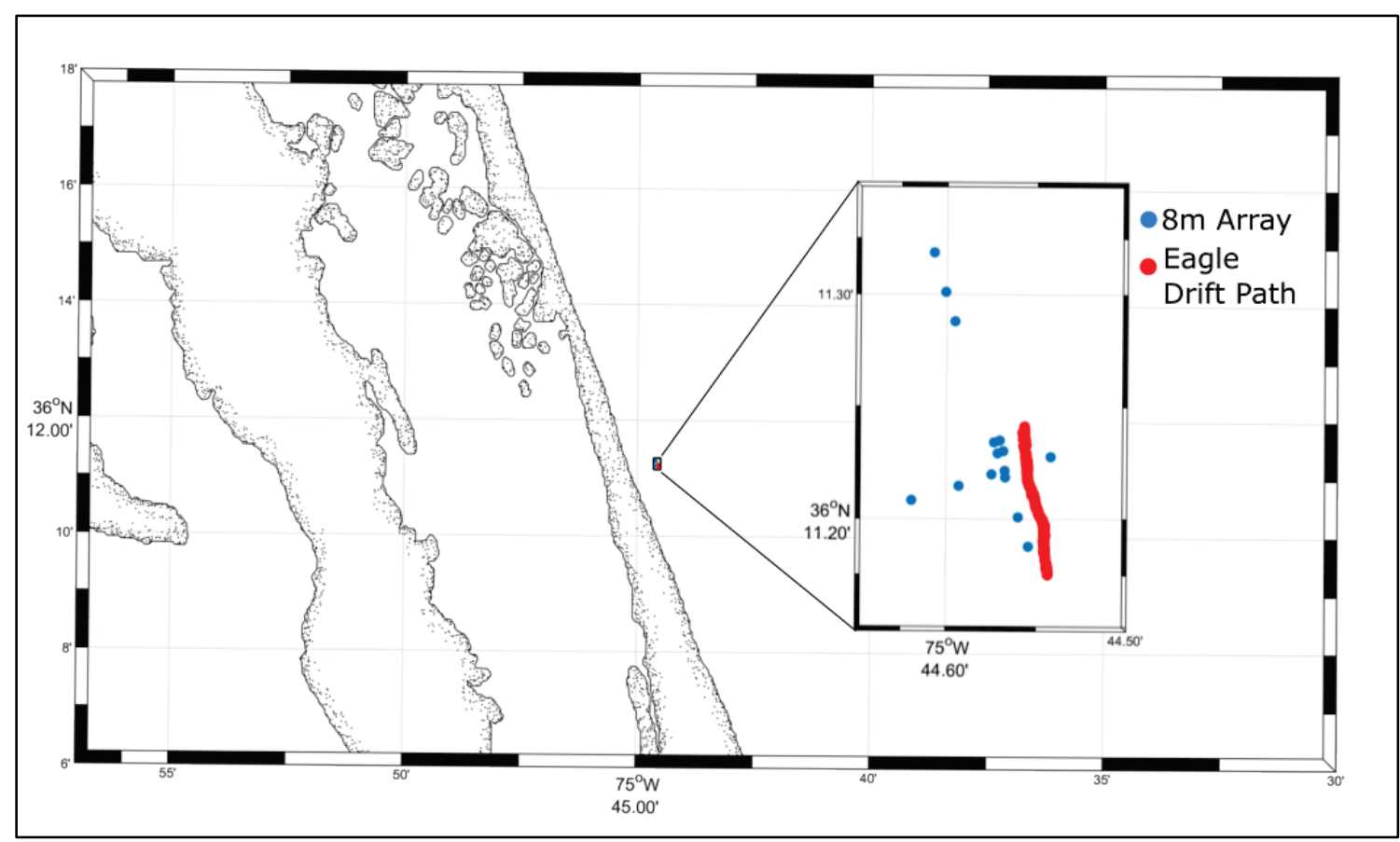

Figure 2. Map showing the geographic location of the field test. The inset panel shows $8 \mathrm{~m}$ array (blue dots) and the drift path of the Eagle (red dots).

The $8 \mathrm{~m}$ array is a wave sensor located near the $8 \mathrm{~m}$ depth contour and has been in operation since $1990^{*}$. It combines 16 synchronized pressure sensors, the data from which are processed as a phased array (Long and Oltman-Shay 1991). An iterative maximum likelihood method is used (Oltman-Shay and Guza 1984) that results in directional spectra of higher resolution than traditional single-point-triplet (SPT) measurements. For the purposes of comparison, the data from the $8 \mathrm{~m}$ array are considered ground truth.

Some INS outputs from the Eagle are listed in Table 1. The different components of the INS gyroscope, accelerometer, and GPS - are listed along with their variable outputs and units. Also listed are the Navstate position and velocity products, which are a fusion of the component systems with barometric pressure sensor, thermistor, and magnetometer data.

\begin{tabular}{|l|l|l|l|l|l|l|l||}
\hline \multicolumn{1}{||l}{ Table 1. INS output with units. } \\
\hline Source & $\begin{array}{l}\text { GPS } \\
\text { clock }\end{array}$ & Gyro & Accelerometer & $\begin{array}{l}\text { Raw } \\
\text { GPS } \\
\text { position }\end{array}$ & $\begin{array}{l}\text { Raw } \\
\text { GPS } \\
\text { velocity }\end{array}$ & $\begin{array}{l}\text { Navstate } \\
\text { position }\end{array}$ & $\begin{array}{l}\text { Navstate } \\
\text { velocity }\end{array}$ \\
\hline Measurement & Time & $\begin{array}{l}\text { Roll, } \\
\text { Pitch, } \\
\text { Yaw }\end{array}$ & $\begin{array}{l}\text { Heave, Surge, } \\
\text { Sway }\end{array}$ & $\begin{array}{l}\text { North, } \\
\text { East, } \\
\text { Down }\end{array}$ & $\begin{array}{l}\text { North, } \\
\text { East, } \\
\text { Down }\end{array}$ & $\begin{array}{l}\text { North, } \\
\text { East, } \\
\text { Down }\end{array}$ & $\begin{array}{l}\text { North, } \\
\text { East, } \\
\text { Down }\end{array}$ \\
\hline Units & $\mathrm{s}$ & $\mathrm{rad} / \mathrm{s}$ & $\mathrm{ft} / \mathrm{s}^{2}$ & $\mathrm{ft}$ & $\mathrm{ft} / \mathrm{s}$ & $\mathrm{ft}$ & $\mathrm{ft} / \mathrm{s}$ \\
\hline \hline
\end{tabular}

\footnotetext{
* Hathaway, K. K., C. O. Collins III, W. A. Birkemeier, P. J. Dickhudt, and M. F. Forte. Accepted. Topographic and Bathymetric Survey, Wave, and Wind Records from the USACE Field Research Facility 1980 to 2018, Scientific Data.
} 
SURFACE ELEVATION AND 1D FREQUENCY SPECTRA: The heave signal from the vertical accelerometer was transformed from the UAV frame of reference to an Earth reference frame via coordinate transformation (à la Anctil et al. 1994). Vertical displacement was calculated by double integrating the Earth-reference heave and is referred to simply as "heave." Figure 3 shows the Eagle heave along with the Navstate-down position product (henceforth, just Navstate), both are demeaned and detrended. A non-stationary trend from 1500 to $1700 \mathrm{~s}$ was removed from the Navstate signal. This non-stationary section was likely a result of a temperature change shortly after contacting the water ${ }^{*}$. Temperature is one of the variables used to produce the Navstate product and can be sensitive to a temperature change (e.g., as it transitioned from air to water).

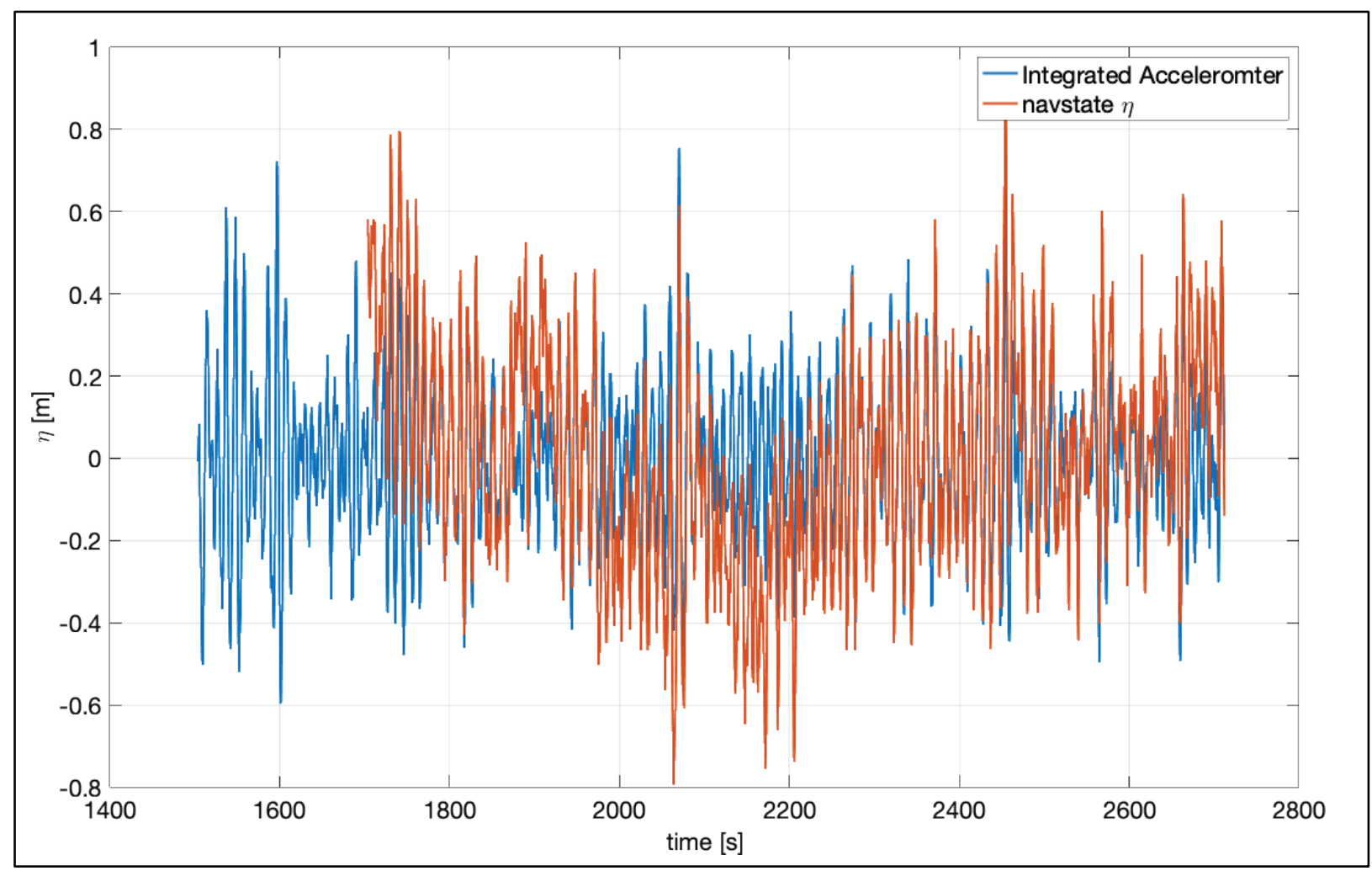

Figure 3. Representation of sea surface elevation, $\eta$, as derived from heave (blue line) and the Navstate down position (red line).

As shown in Figure 3, the integrated accelerometer and Navstate signals are generally in phase, but there are low-frequency signatures in the Navstate data that are not in the heave data. While this does not have a significant effect on spectral analysis due to the signals being high-pass filtered, it would be significant if performing zero-crossing analysis. After removing the nonstationary portion of the Navstate signal, 1D frequency spectra were calculated via fast Fourier transform. The resulting spectra are plotted in Figure 4 along with spectra from the $8 \mathrm{~m}$ array and reference lines for the slope of the spectral tail.

\footnotetext{
* E. Johnson. Personal communication. Pennsylvania State University.
} 


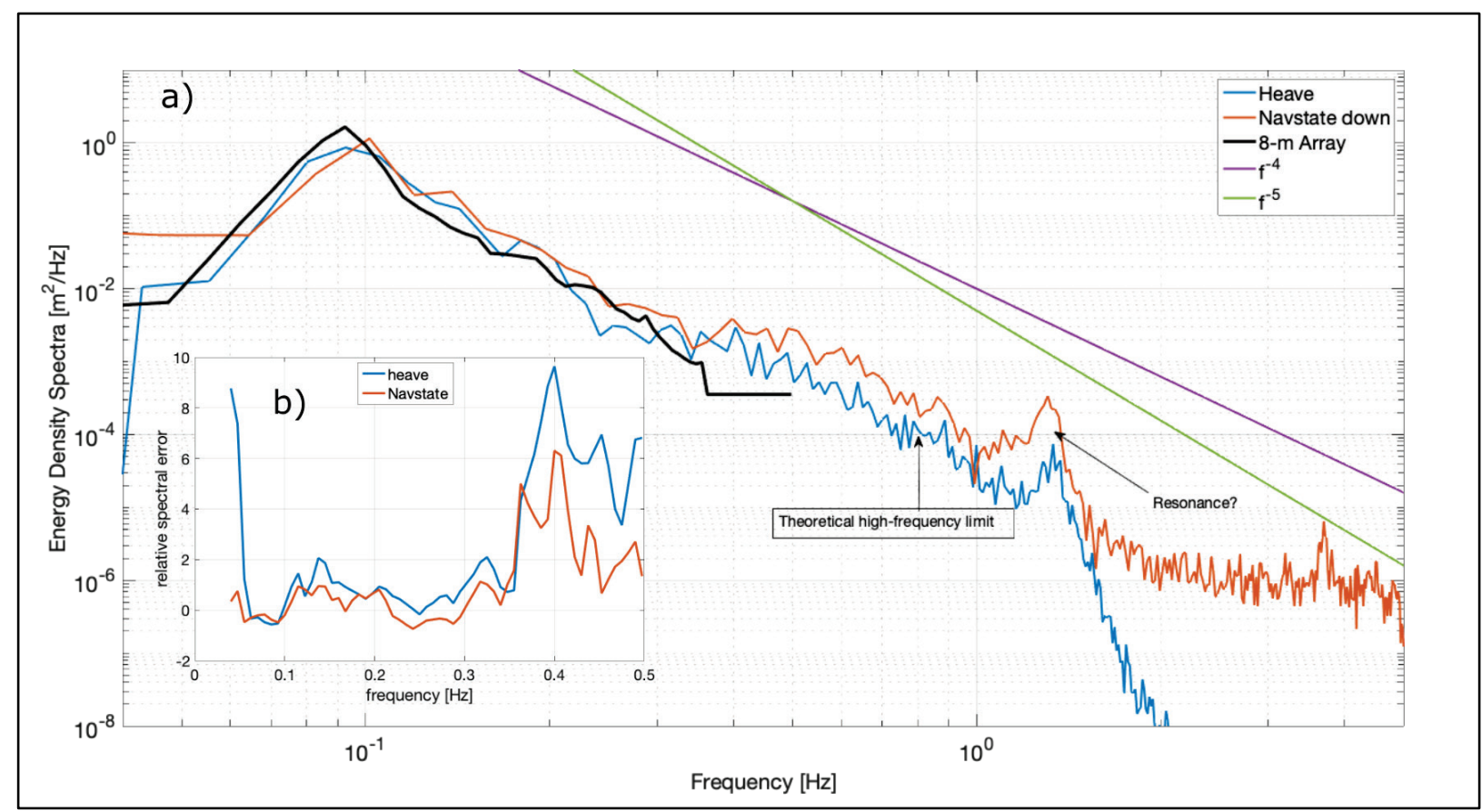

Figure 4. a) 1D frequency spectra from the $8 \mathrm{~m}$ array (black line), heave (blue line), Navstate (red line), $\mathrm{f}-4$ reference slope (purple line), and $\mathrm{f}-5$ reference slope (green line). b) The relative error of the heave spectrum (blue line) and Navstate spectrum (red line) relative to the $8 \mathrm{~m}$ array.

The $8 \mathrm{~m}$ array and Eagle-heave spectra agree in the very low frequencies $(0.05-0.07 \mathrm{~Hz})$, below the peak frequency, whereas the Eagle-Navstate spectrum is approximately an order of magnitude higher in this range. This can be clearly seen in relative error plotted in Figure $4 \mathrm{~b}$ ). This suggests that the low-frequency energy in the Eagle-Navstate signal is spurious. Both spectra from the Eagle are similar from 0.07 to $0.40 \mathrm{~Hz}$ and are reasonable from 0.40 to $0.80 \mathrm{~Hz}$. The frequency of approximately $0.80 \mathrm{~Hz}$ corresponds to a wavelength double the diameter of the Eagle and the limit at which the Eagle can adequately respond to the sea surface. There is a small peak in the Eagle spectra at approximately $1.50 \mathrm{~Hz}$. It is suspected this small peak is related to the resonant frequency of the Eagle's response function, but confirmation of this would require further investigation.

Both spectra from the Eagle compare favorably against the $8 \mathrm{~m}$ array from 0.07 to $0.35 \mathrm{~Hz}$. The $8 \mathrm{~m}$ array data have a high-frequency cutoff to deal with the attenuation of the wave-pressure signal with depth. For comparing spectral metrics, the spectra, $S(f)$, were interpolated to match the frequency resolution of the $8 \mathrm{~m}$ array with an upper frequency bound of $0.355 \mathrm{~Hz}, f_{L}$, and a lowerfrequency bound of $0.040 \mathrm{~Hz}, f_{U}$. The significant wave height $(H s)$, 4th power period $\left(T_{p 4}\right), 4$ th spectral moment $\left(m_{4}\right)$, and spectral width $(v)$ were calculated as follows:

$$
\begin{gathered}
m_{n}=\int_{f_{L}}^{f_{U}} f^{n} S(f) d f \\
H s=4 \sqrt{m_{0}} \\
T_{p_{4}}=\frac{\int_{f_{L}}^{f_{U}} S(f)^{4} d f}{\int_{f_{L}}^{f_{U}} f S(f)^{4} d f}
\end{gathered}
$$




$$
v=\sqrt{\frac{m_{0} m_{2}}{m_{1}^{2}}-1}
$$

$H s$ gives an indication of the average of the highest one-third of waves, $T_{p} 4$ gives the wave period near the peak of the spectrum, $m_{4}$ is proportional to mean-square-slope (important for remote sensing), and $v$ is width of the spectrum. The values for each spectrum are given in Table 2, as well as the relative error against the $8 \mathrm{~m}$ array.

\begin{tabular}{|c|c|c|c|c|c|}
\hline & $\begin{array}{c}8 \mathrm{~m} \\
\text { Array }\end{array}$ & Navstate & $\begin{array}{c}\text { Navestate } \\
\text { Error }\end{array}$ & Heave & $\begin{array}{l}\text { Heave } \\
\text { Error }\end{array}$ \\
\hline $\mathrm{Hs}$ & 0.84 & 0.82 & $-2 \%$ & 0.77 & $-8 \%$ \\
\hline$T_{p 4}$ & 10.88 & 9.96 & $-8 \%$ & 10.6 & $-3 \%$ \\
\hline $\mathrm{m}_{4}$ & 8.56E-05 & $1.28 \mathrm{E}-04$ & $50 \%$ & 9.12E-05 & $7 \%$ \\
\hline $\mathbf{v}$ & 0.31 & 0.32 & $3 \%$ & 0.3 & $-3 \%$ \\
\hline
\end{tabular}

Peak periods were nearly the same between each spectrum, and the significant wave height was within the expected sampling variability. The only significant error was Navstate $m 4$, which indicates too much energy in the high frequencies. Combined with low-frequency energy that is likely spurious, the heave signal compares best against the $8 \mathrm{~m}$ array and is used for calculating directional spectra in the next section.

2D DIRECTIONAL-FREQUENCY SPECTRUM: Visual observations of the Eagle's movement as it was adrift indicated that it may not have followed the slope of the sea surface, as assumed for heave-pitch-roll analysis. Instead of tilting to match the slope of the sea surface, a rotor from Eagle would pierce the surface of the front face of a wave, exit the water as a wave passed, and hang suspended out of the water over a wave's back face. The Navstate north and east velocities were less affected by drift than the Navstate north and east position signals (not shown). Therefore, directional spectra were calculated from a combination of heave and the Navstate north and east velocities.

SPT analysis (Longuet-Higgins et al. 1963) begins with cross-correlating the three signals resulting in co- and quadrature (quad)-spectra, $\mathrm{C}_{\mathrm{xx}}$ and $\mathrm{Q}_{\mathrm{xx}}$. The co- and quad-spectra are directly related to the first five directional coefficients, equivalent to the first five Fourier coefficients in a series approximation to the full direction-frequency spectrum, $E(f, \theta)$.

$$
a_{n}(f)+i b_{n}(f)=\frac{1}{\pi} \int_{0}^{2 \pi} e^{i n \theta} E(f, \theta) d \theta
$$

The relationship between the coefficients, $\left(a_{n}, b_{n}\right)$, and $\mathrm{C}_{\mathrm{xx}}$ and $\mathrm{Q}_{\mathrm{xx}}$, depends on the specific three properties measured (for general relations, see Young [1999]). The UAV was treated as a displacement system using the vertical signal and two horizontal velocities, $\eta(t), u(t)=\dot{\mathrm{x}}(t)$, and $v(t)=\dot{y}(t)$. 
The underlying assumptions are that the platform responds in the vertical to the sea surface and it follows the particle motion of the waves in a quasi-Langrangian frame for the frequency scales of interest, usually $0.05-0.5 \mathrm{~Hz}$. The 1D frequency spectrum, $S(f)$, is the auto-spectrum of the vertical displacement, $\eta(\mathrm{t})$.

$$
a_{0}(f)=C_{11}(f)=\int_{0}^{2 \pi} E(f, \theta) d \theta=S(f)
$$

Where the cross-spectral subscripts are a convenient notation to indicate the combination of signals, here $\eta(\mathrm{t})$ is designated as 1 . The cross-spectral subscripts $N$ and $E$ refer to the north- and east-direction velocities, respectively. The relationship between the co- and quad-spectra and the four directional coefficients are now

$$
\begin{gathered}
a_{1}=\frac{C_{N 1}}{\sqrt{\left(C_{N N}+C_{E E}\right) C_{11}}} \\
b_{1}=\frac{C_{E 1}}{\sqrt{\left(C_{N N}+C_{E E}\right) C_{11}}} \\
a_{2}=\frac{C_{N N}-C_{E E}}{C_{N N}+C_{E E}} \\
b_{2}=\frac{2 C_{N E}}{C_{N N}+C_{E E}}
\end{gathered}
$$

To produce directional spectra comparable to the higher resolution of the $8 \mathrm{~m}$ array, the iterative maximum likelihood method (Pawka 1983), as implemented through the open source DiWASP (Johnson 2002) MATLAB toolbox, was used.

Directional spectra from the $8 \mathrm{~m}$ array and the Eagle are shown in Figure 5 on a log scale. Qualitatively, the two different directional spectra tell a similar story about the local wave system. The peak frequency is a near $\sim 0.10 \mathrm{~Hz}$ and emanates from the east $(\sim 90 \mathrm{deg})$ with high directional spread. The directional spread narrows as the frequency increases and tapers into a ridge. As the frequency increases, the ridge veers towards the wind direction, which is out of the south. There is a close correspondence between magnitude, shape, and extent of the wave systems as measured by the two sensors, although the Eagle spectrum is much less smooth. 


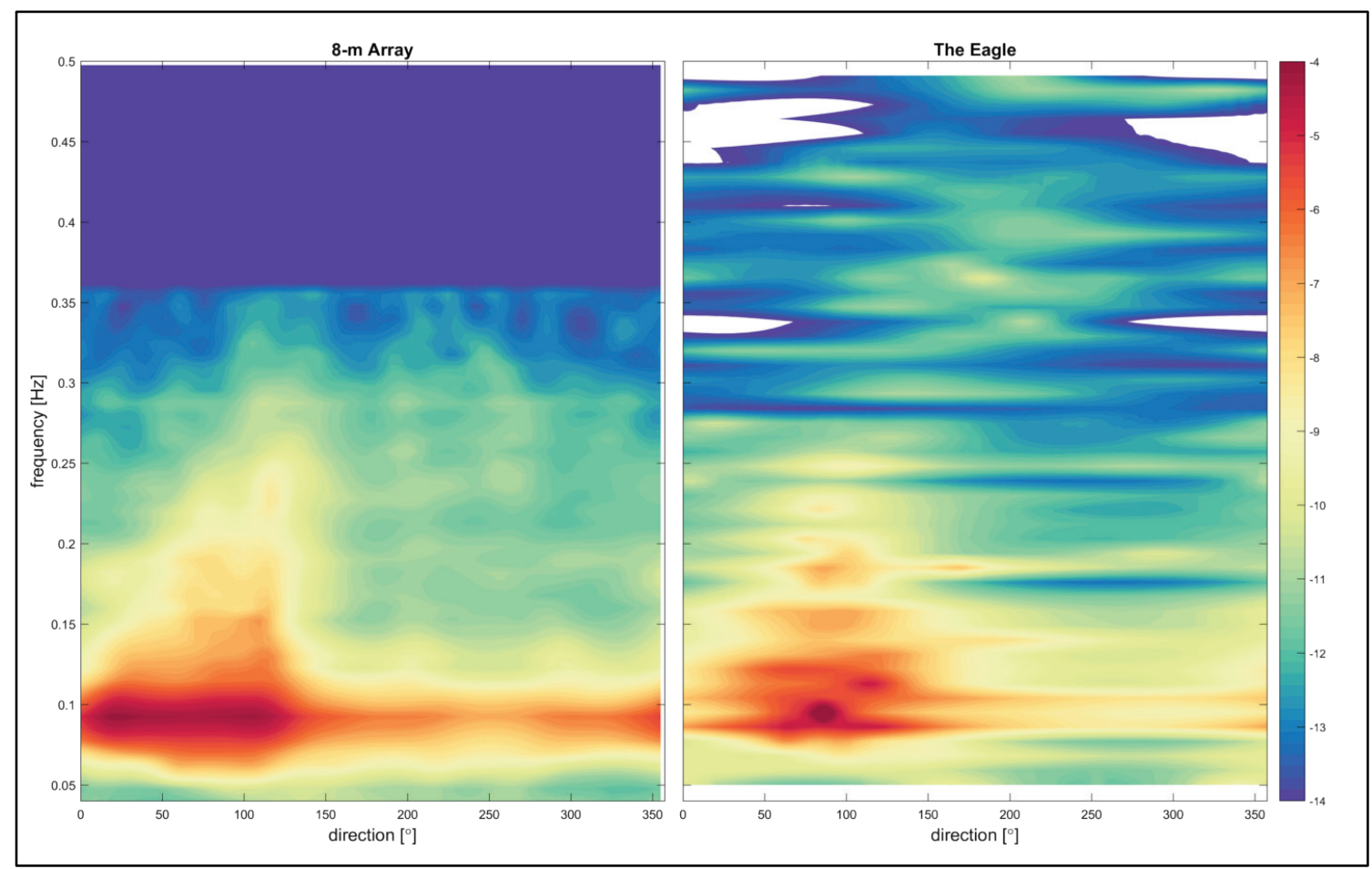

Figure 5. Direction-frequency spectra from the $8 \mathrm{~m}$ array (left) and the Eagle (right). The color scale indicates the spectral density $\left[\mathrm{m}^{2} / \mathrm{Hz} / \mathrm{deg}\right]$ on a log scale.

Such close correspondence between the data provides a proof of concept and opens another avenue for deriving in situ wave information. This work shows that any floating system with an INS could potentially produce directional wave measurements. In this case, no major modifications to the UAS were required. The implication is that these measurements do not produce additional design constraints. Note that it is important that the system move freely with the sea surface, which requires that the flight operator power down the rotors after making an aqueous landing.

For the testing described here, the conditions were conducive for measuring waves from a small, SPT platform - low steepness, single-peaked, long, steady swell, and outside the surf zone. The next step would be more comprehensive quantitative evaluation. Conducting similar tests in a range of conditions would provide data to constrain the working conditions of this platform. Such an evaluation would require many hours of data in diverse conditions and use of similar spectral and data adaptive methods.

ADDITIONAL INFORMATION: This CHETN was prepared as part of the Office of Naval Research, Coastal Geosciences program, managed by Reginald Beach, and prepared by Dr. Clarence O. Collins and Dr. Katherine Brodie, ERDC, Coastal and Hydraulics Laboratory (CHL), Coastal Analysis and Observations Branch, Duck, NC. Questions pertaining to this CHETN may be directed to Dr. Clarence O. Collins (Clarence.O.Collins@usace.army.mil). The Eagle was built and operated by a team headed by Eric Johnson (Pennsylvania State) and included the members from the US Naval Research Laboratory. Field operations were organized by Jason Pipes, Rob Mitchell, and Bill Ledford. Steve Elgar assisted in field work. 
This ERDC/CHL CHETN should be cited as follows:

Collins, Clarence O. III, and Katherine Brodie. 2021. In Situ Measurements of Directional Wave Spectra from an Unmanned Aerial System. ERDC/CHL CHETNIV-128. Vicksburg, MS: US Army Engineer Research and Development Center. http://dx.doi.org/10.21079/11681/41701

\section{REFERENCES}

Anctil, F., M. A. Donelan, W. M. Drennan, and H. C. Graber. 1994. "Eddy-Correlation Measurements of Air-Sea Fluxes from a Discus Buoy." Journal of Atmospheric and Oceanic Technology 11(4): 1144-1150.

Brodie, K. L., B. L. Bruder, R. K. Slocum, and N. J. Spore. 2019. "Simultaneous Mapping of Coastal Topography and Bathymetry From a Lightweight Multicamera UAS." IEEE Transactions on Geoscience and Remote Sensing 57(9): 6844-6864.

Collins III, C. O. 2012. In Situ Wave Measurements: Sensor Comparison and Data Analysis. MS thesis. University of Miami.

Collins III, C. O., B. Lund, R. J. Ramos, W. M. Drennan, and H. C. Graber. 2014. "Wave Measurement Intercomparison and Platform Evaluation during the ITOP (2010) Experiment." Journal of Atmospheric and Oceanic Technology 31(10): 2309-2329.

Collins III, C. O., W. E. Rogers, A. Marchenko, and A. V. Babanin. 2015. "In Situ Measurements of an Energetic Wave Event in the Arctic Marginal Ice Zone." Geophysical Research Letters 42(6): 1863-1870.

Holman, R. A., K. L. Brodie, and N. J. Spore. 2017. "Surf Zone Characterization Using a Small Quadcopter: Technical Issues and Procedures." IEEE Transactions on Geoscience and Remote Sensing 55(4).

Johnson, D. 2002. DIWASP, a Directional Wave Spectra Toolbox for MATLAB ${ }^{\circledR}$ : User Manual. Center for Water Research, University of Western Australia.

Lenain, L., and W. K. Melville. 2014. "Autonomous Surface Vehicle Measurements of the Ocean's Response to Tropical Cyclone Freda.” Journal of Atmospheric and Oceanic Technology 31(10): 2169-2190.

Long, C. E., and J. M. Oltman-Shay. 1991. Directional Characteristics of Waves in Shallow Water. CERC-TR-91-1. Vicksburg, MS: Coastal Engineering Research Center.

Longuet-Higgins, M. S., D. E. Cartwright, and N.D. Smith. 1963. "Observations of the Directional Spectrum of Sea Waves Using the Motions of a Floating Buoy." Ocean Wave Spectra, Proc. Conf., Easton, MD, May 1-4. New Jersey: Prentice Hall.

Oltman-Shay, J., and R. T. Guza. 1984. "A Data-Adaptive Ocean Wave Directional-Spectrum Estimator for Pitch and Roll Type Measurements.” Journal of Physical Oceanography 14(11): 1800-1810.

Pawka, S. S. 1983. "Island Shadows in Wave Directional Spectra." Journal of Geophysical Research: Oceans 88(C4): 2579-2591.

Reineman, B. D., L. Lenain, N. M. Statom, and W. K. Melville. 2013. "Development and Testing of Instrumentation for UAV-Based Flux Measurements within Terrestrial and Marine Atmospheric Boundary Layers." Journal of Atmospheric and Oceanic Technology 30(7): 1295-1319.

Thomson, J., J. B. Girton, R. Jha, and A. Trapani. 2018. "Measurements of Directional Wave Spectra and Wind Stress from a Wave Glider Autonomous Surface Vehicle." Journal of Atmospheric and Oceanic Technology 35(2): 347-363. 
Tucker, M. J. 1952. “A Wave-Recorder for Use in Ships.” Nature 170(4329): 657-659.

Tucker, M. J., and E. G. Pitt. 2001. Waves in Ocean Engineering. Elsevier Ocean Engineering Series, Vol. 5. Elsevier Science. Amsterdam, Netherlands: Elsevier Publishing Company.

Young, I. R. 1999. Wind Generated Ocean Waves, Vol. 2. Amsterdam, Netherlands: Elsevier Publishing Company.

Yurovskaya, M. V., V. N. Kudryavtsev, A. S. Shirokov, and I. Y. Nadolya. 2018. "Field Measurements of the Sea Surface Wave Spectrum from Photos of Sunglitter Taken from Drone." Sovrem. Probl. Distantsionnogo Zondirovaniya Zemli Kosmosa 15: 245-257.

NOTE: The contents of this technical note are not to be used for advertising, publication, or promotional purposes. Citation of trade names does not constitute an official endorsement or approval of the use of such products. 